Proceedings of the 1993 IEEE Intemational Engineering Management Conference (IEMC)

Published by IEEE, Hyau Regency, New Delhi, India, December 17-18, 1993

\title{
ROLE OF STRATEGIC PLANNING IN ENGINEERING MANAGEMENT
}

\author{
Kumar Krishen, Ph.D. \\ NASA Johnson Space Center \\ Houston, Texas 77058
}

\begin{abstract}
:
Today, more than ever before, engineers are faced with uncertain and sometimes chaotic environments in which to function. The traditional roles of an engineer to design, develop, and streamline a manufacturing process for a product are still valued and relevant. However, the need for an engineer to participate in the process of identifying the product to be developed, the schedule and resources required, and the goal of satisfying the customer, has become paramount to achieving the success of the enterprise. When we include these endeavors in the functions of an engineer, management of "engineering" takes on a new dimension. In this paper, the ramifications of the changing and increased functions of an engineer and consequent impacts on engineering management are explored. The basic principles which should be invoked in order to embrace the new environment for engineering management are outlined. The ultimate finding of this study is that the enterprise strategic plan should be developed in such a way as to allow engineering management to encompass the full spectrum of the responsibilities of engineers. A consequence of this is that the fundamental elements of the strategic process can bestbe implemented through a project team or group approach. The paper thus concentrates on three areas: evolving environment, strategic plan, and ways to achieve enterprise
\end{abstract} success.

\section{Introduction}

With the advent of the communications age, the impetus to develop unique products and processes has accelerated. Indeed, this is an era of innovation that is chiefly brought about as a result of commercial benefits of technology realized by advanced nations. As the barriers for trade and commerce are vanishing, competitiveness has taken on a new dimension. Survival of commercial enterprises is a direct function of how well they can assimilate and adopt new and productive methods to control cost, innovate products, and preserve the Earth's environment. In the past we emphasized products, and the applicability of the product determined its commercial potential. In general, the management of industries became the management of product development. Of course, the product had to meet a certain set of specifications and delivery deadlines. The customer traditionally "appeared" at the end of the chain. This approach was fundamentally based on the application of a proven manufacturing process to product development. Today, new products and processes are the drivers of commercial rhythm. Furthermore, even for routine products, the processes and management of these processes

- are continually changing. In successful enterprises internal product development and process changes are uniquely coupled to the market forces and commercial environment. This implies that there is continuous customer feedback and evaluation of the product performance through a structured process which is used to generate new and modified strategies for product development.

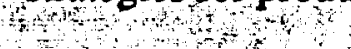

Product performance and customer feedback are closely coupled with the political and commercial environment of local and global communities. In addition to cultural factors, 
product needs are driven by the economic forces which originate from the basic precepts of demand and supply. The advent of fast communications and transportation has made global markets more accessible to a majority of industries willing to compete for the world market share. Through these new market trends, several themes emerge: (1) the present industries and commercial enterprises must constantly gauge the political and commercial environment on a local and global scale; (2) there should be continuous feedback and evaluation of customer satisfaction; (3) the adoption of new technology and advanced processes which have a major influence on product development must be an integral part of the implementation plan; and (4) partnering opportunities to enhance products and/or reduce costs should be explored. The teaming concept has its share of disadvantages in that one enterprise's success can depend on the health of its partners. However, its paramount advantage of enabling the development and production of superior products at low costs outweighs most of its disadvantages. Finally, the overall strategic process (figure 1) for an enterprise derives its health not only from management, but from scientists and engineers (S\&E's). The appropriate involvement of $S \& E$ 's in all aspects of the process is crucial to the success of the enterprise. This shall be discussed in detail in this paper.

\section{Evolving Political and Commercial Environment}

The end of the cold war and the evolution of the European Economic Community (ECC) are among the many political and economic changes affecting the global mosaic for commercial activities. The ultimate results of the global political strife in commercial terms cannot be fully predicted. Based on the current trends, however, the following generalizations can be made: (1) many nations will strive to better the standard of living of their citizens; economic well being is considered a top priority by most citizens throughout the world; (2) communications and medical health technologies will be fervently

Political and Commercial Environment

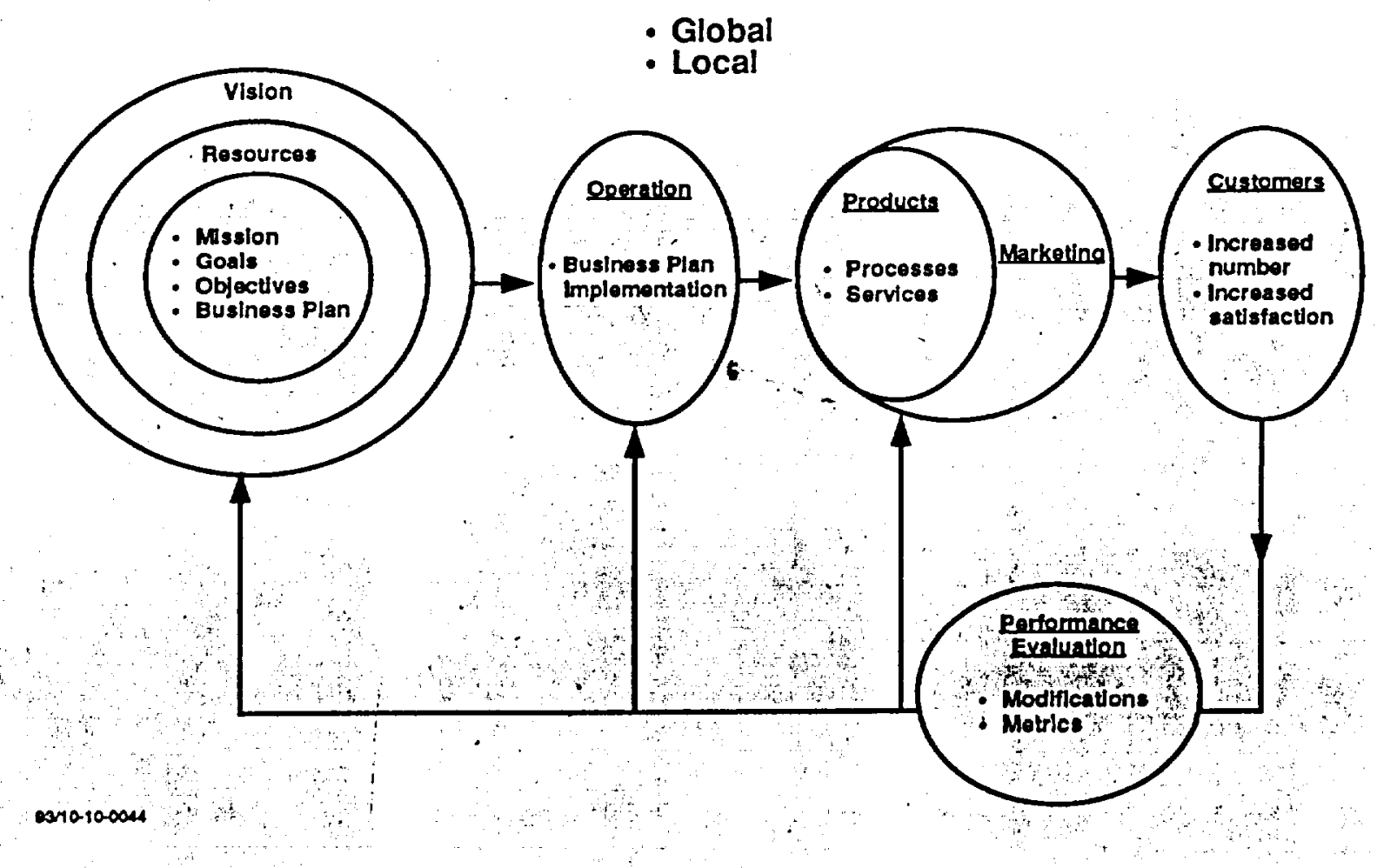

Figure 1.-Enterprise strategic process. 
sought by most of the nations; (3) unique technologies for transportation, housing, agriculture, and manufacturing will be in higher demand than ever before; (4) there will be more emphasis placed on a clean Earth environment and technologies which will assure this, so those technologies which will clean the deteriorated environment will be in greater demand; and (5) public safety and crime prevention technologies and systems will be of great concern to technologically advanced nations.

As the pace of technology continues to accelerate, the adoption of new technologies will create somewhat of a dilemma for all sectors of the economy. On a personal level, it means new investments for consumers. On a commercial level, it will require new marketing strategies and sales infrastructures. In the area of manufacturing, it will mean new assembly lines and processes. Finally, at all levels, it will require new training and associated tools. Thus, the "transitions" to new products and services will take on a new. dimension in their significance. The nations, businesses, and individuals which can adopt these new products and processes for increasing productivity and reducing costs, will push forward on the economic scale. It would seem that two strategies will ease this transitional concern: (1) technologies and processes must "bridge" the new and old infrastructures so that the use of existing resources and enterprise investments can be assured and (2) flexible strategies and implementation plans will have to anticipate technological changes and find ways to adopt new technologies and processes without serious disruptions.

Based on the comments made in this section, we can anticipate a greater demand for new products and services, provided these do not make existing substantial investments and infrastructures obsolete. In addition, an emphasis on free trade and entrepreneurship will continue. In order to ascertain market share, many enterprises will team up with others to develop systems which can then compete on the international level. This "distributed" manufacturing will draw its impetus from the specialized interests each enterprise will have in maintaining a leading edge in certain processes and technologies. In turn, new enterprises specializing in "systems integration" will be needed for the overall product development and manufacturing.

\section{Strategic Planning Process}

A Strategic Plan is the backbone of every successful business enterprise. In brief, it consists of vision, mission, goals, objectives, implementation plan(s), products and services, customers and related schedules (figure 2). It

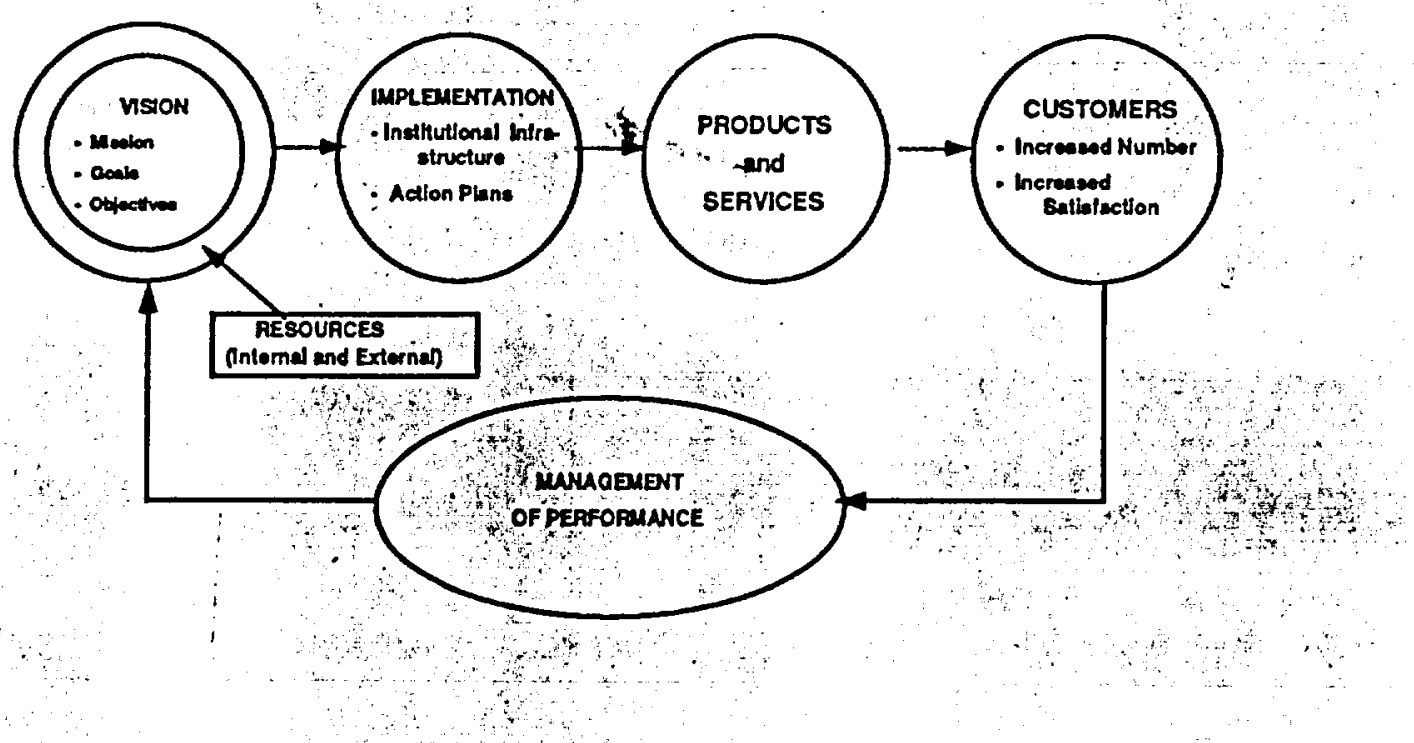

Figure 2.-Elements of strategy. 
derives its roots from a business plan wherein forecasts for products and services have been developed. The plan considers both present internal and external resources and anticipated evolution of these as the products continue to be developed. The process which generates the plan is known as the "Strategic Process." This process organizes and recognizes two major structures of a successful enterprise: (1) the flexibility to adopt needed changes in products and processes and (2) the existing physical and investment infrastructure.

In most enterprises, developing a strategic plan is a periodic concern. Most enterprises develop plans on an annual, biannual, or 5-year basis. Inputs to this plan are sought from all levels of management. In most cases, the plan is issued to employees for review, and their comments and suggestions are used for the final version. A Strategic Planning Process (SPP), on the other hand, is a continuous activity which deals with the changes, both short-term and long-term, that should be made to the Strategic Plan as a result of unknown variations in political and economic environment or technological breakthroughs.

As was elaborated in the previous section, we are dealing with a time of great changes. Accordingly, our approach to SPP becomes a crucial part of an enterprise. In addition to external changes, the enterprise must accommodate any possible changes that might be dictated by measurement of performance. Measurement of performance and identification of needed improvements is one of the most significant parts of the SPP. Performance is a composite function of internal measurement provided by employees and those provided externally by customers and other enterprise team members. Metrics for this performance must be agreed upon and applied. Both statistical and deterministic approaches using computerized routines for efficiency should be used in gauging performance. Interpretation of the results and subsequent actions that can be undertaken also require planning and expertise. $A$ byproduct of the successful analysis of performance results should be options for actions that can be undertaken to boost performance to the expected and planned levels. The entire segment of SPP having to do with performance is called "Management of Performance." As shown in figure 2, it, along with political and economic environment, forms a crucial feedback loop for the overall SPP.

\section{Strategic Engineering Management}

In the previous sections, we have idenfified a number of factors which result in stresses and strains on the strategic plan of an enterprise. For the most part, these wanted and unwanted perturbations are not predictable. Even when the events are predictable, their influence on the health of the enterprise is difficult to calculate. So, we must embark on a process which provides not only assessment of the current events and a good extrapolation to future possibilities, but also one which identifies options for implementing corrective actions when needed. This management process has to be implemented in such a way that the operations of the enterprise continue with planned and productive perturbation as the options for change are implemented. This means that "teams" with expertise in various aspects, including design, development, manufacturing, marketing, customer feedback and budgeting of the process, should be formed to provide the needed feedback and implementation options. The final selection of the changes in a strategic plan and its implementation can then be carried out by the executive management of the enterprise. In this context, the role of engineers and scientists becomes broader than just the confines of design, development, and manufacturing. This will be called Strategic Engineering Management (SEM). In order to implement $S E M$, we should recognize that the most productive area for an enterprise is where it understands and utilizes the strengths of "teams," technology, and "political and economic environment (figure 3 ).

The time and location-dependent nature of the three factors (shown in figure 3 ) should be 


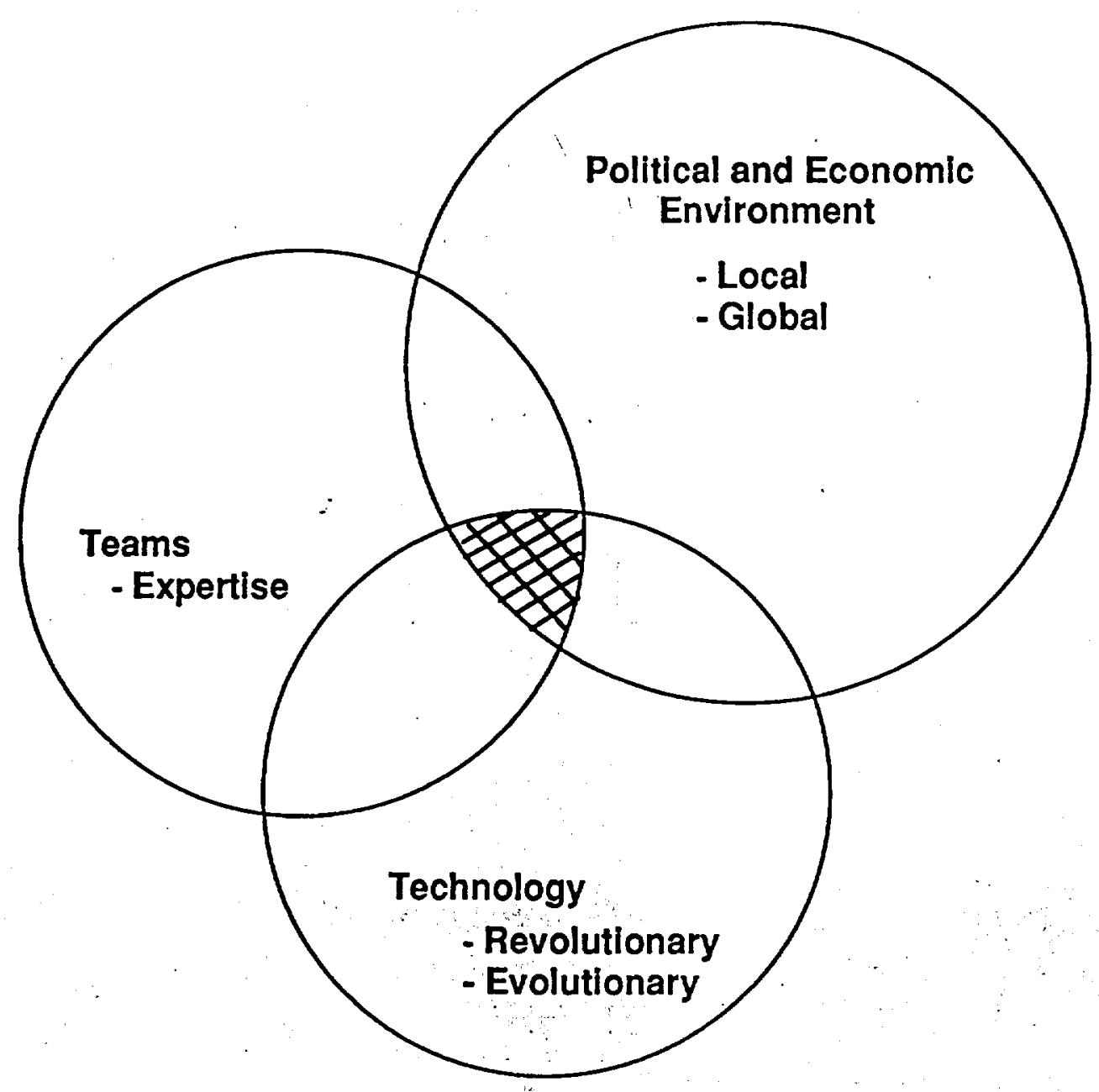

Figure 3.- Area of operation for a successful enterprise.

recognized as part of the strategic process. It then means that management has a fixed structure which is dictated by the strategic plan and aided by the "teams" which can react to external forces brought about by the rapid pace of technology and political and economic environment. These two parallel structures constitute the SEM which will allow enterprises with flexible strategies to succeed:

Finally, the future of an enterprise will, in part, depend on the price at which it can offer its products and services to customers, assuming their quality is the same as other competing enterprises. So, maximization of efficiency becomes part of the performance management mentioned earlier in this paper. These efficiencies should result from the SEM and should also be included in the feedback process (figure 4).

\section{Concluding Remarks}

We are continually facing new political and economic environments and the influx of new technologies. In order to benefit from these -changes, a flexible strategic plan should be developed with a strategic process in place to reflect needed product and process changes in a timely manner. Organizations which have adopted these strategic planning processes (SPP) have not only survived, butflourished in uncertain economic and political environments. 1 To manage the organizations according to the SPP, we need to develop strategic engineering management to replace the traditional role of scientists and engineers in an enterprise. Basically, an engineer or scientist is a member of the team(s) which will identify options to be implemented to advance 


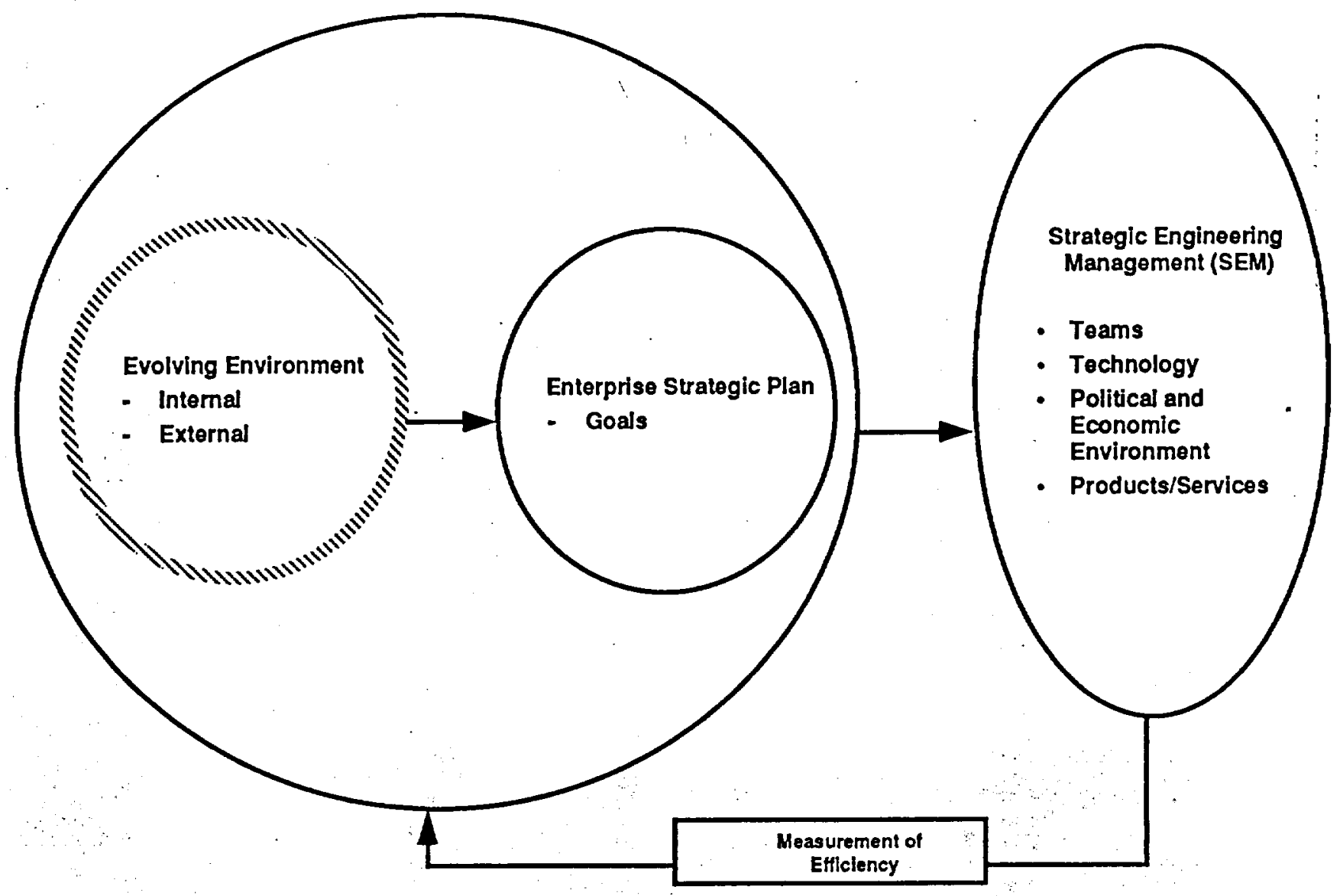

Figure 4.- Management process responsive to strategic plan.

products and processes and gain an edge over the competition. In this context, the engineers and scientists then become an engine for the overall process, and the executives control the final destiny. of the enterprise.

\section{Acknowledgment}

The author is grateful to Ms. Jennifer Mason-Korecki of the NASA Johnson Space
Centerand Ms. Anjala K. Kachroo for their valuable comments and suggestions which were incorporated in the final version of the paper.

\section{Reference}

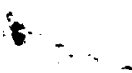

[1] John J. Donovan, Strategic Weapons and Tactics for Executives. Cambridge, MA: Cambridge Technology Group, 1989. 